\title{
GORDOFOBIA NA MODA PLUS SIZE
}

\author{
Plus size fashion fatphobia \\ Gordofobia en la moda plus size
}

\author{
Maria Luisa Jimenez Jimenez \\ Universidade Federal de Mato Grosso \\ Filósofa, mestra e doutora em Estudos de Cultura Contemporânea, Faculdade de Artes e Comunicação, \\ pela Universidade Federal de Mato Grosso (UFMT). Participa do Pesquisa Gorda, Grupo de Estudos \\ Transdisciplinares das corporalidades gordas no Brasil. E-mail: malujjimenez@gmail.com
}

RESUMO Publicado em 2019, o livro De gorda a plus size: a moda do tamanho grande propõe um desvendamento acerca dos corpos gordos femininos e a moda plus size como estratégia biopolítica. O livro propõe uma discussão sobre os significados contidos nos discursos sociais sobre o corpo feminino gordo e nos discursos midiáticos de marcas de moda que produzem tamanhos grandes. A leitura nos permite entender como os discursos de poder são construídos, a partir da preferência pela mulher magra, denunciando o estigma da gordofobia nesse cenário: a indústria da moda.

PALAVRAS-CHAVE Gordofobia, Moda plus size, Mulheres gordas, Biopolítica.

ABSTRACT Published in 2019, the book De gorda a plus size: a moda do tamanho grande (From fat to plus size: big size fashion) proposes an unveiling about female fat bodies and plus size fashion as a biopolitical strategy. The book proposes a discussion about the meanings contained in the social discourses about the fat female body and in media speeches by fashion brands that produce large size clothes. The reading allows us to understand how the discourses of power are constructed, from the preference for the thin woman, denouncing the stigma of fatphobia in this scenario: the fashion industry.

KEYWORDS Fatphobia, Plus size fashion, Fat women, Biopolitics.

RESUMEN Publicado en 2019, el libro De gorda a plus size: a moda do tamanho grande (De gorda a plus size: la moda de la talla grande) propone una revelación acerca de los cuerpos gordos femeninos y la moda plus size como estrategia biopolítica. El libro discute los significados en los discursos sociales sobre el cuerpo femenino gordo y en los discursos de los medios de comunicación de marcas de moda que producen tamaños grandes. La lectura nos permite entender como los discursos de poder son construidos a partir de una preferencia por la mujer magra, denunciando el estigma de la gordofobia en ese lugar: la industria de la moda.

PALABRAS CLAVE Gordofobia, Moda plus size, Mujeres gordas, Biopolítica.

O livro De gorda a plus size: a moda do tamanho grande, de Aliana Aires, publicado pela editora Estação das Letras e Cores, em 2019, consiste na adaptação de sua tese de doutorado em Comunicação e Práticas de Consumo, pela Escola Superior de Propaganda e Marketing (ESPM), em São Paulo, e apresenta os estudos do corpo transversalizados pela discussão sobre moda, sob uma perspectiva dos estudos de comunicação e consumo.

O livro divide-se em três capítulos e, ao longo deles, a autora apresenta conceitos essenciais para o debate proposto, ao mesmo tempo em que compara o desenvolvimento da moda plus size no Brasil e nos Estados Unidos, país onde se especializou em moda plus size, por meio de um 
doutorado sanduíche, entre 2017 e 2018, na Parsons - The New School, em Nova York, com financiamento da Coordenação de Aperfeiçoamento de Pessoal de Nível Superior (Capes).

De forma transdisciplinar, a discussão entre corpo, comunicação e consumo é aventada, a partir da perspectiva da moda plus size, como uma estratégia biopolítica. Ademais, um resgate histórico dos tamanhos grandes na moda nos posiciona quanto a esse tipo de indústria e de mercado. Além disso, a autora explica não apenas como surge essa terminologia, cujo intuito era o de aumentar as vendas, mas, principalmente, como essa estratégia não diminuiu a gordofobia. Finalmente, apresenta-se ao leitor o motivo de este nicho - que é imenso no mercado - não se desenvolver nem atender à população gorda de maneira efetiva: relaciona-se a um julgamento moral sobre as corporalidades gordas.

A leitura de gorda a plus size: a moda do tamanho grande propõe uma reflexão sobre os corpos gordos (principalmente, femininos), bem como sobre o estigma direcionado a eles. A autora argumenta que, de tão profundo, esse estigma se converte na determinação de como esses corpos devem se vestir e, mais do que isso: delimita o acesso a roupas que caibam em pessoas gordas no mercado. Isso ocorre, pois as roupas para pessoas gordas, além de escassas, são muito caras.

Desse modo, a pergunta que permeia todo o livro é: se pessoas gordas são a maioria da população e essa é uma fatia generosa do mercado, por que a moda plus size ainda é considerada inferior, isto é, subalterna, no tocante a cortes, tecidos, abrangências e tamanhos? Para responder a essa pergunta, Aliana Aires desenvolve algumas ideias-chave acerca dos significados sociais atribuídos aos corpos gordos. Para ela, esses corpos são compreendidos a partir de discursos de poder. Nessa concepção, tais discursos podem ser: 1 . meramente midiáticos ou 2. negativos e patológicos, esse último, comumente difundido de forma estrutural e institucional. Assim, a partir dessa noção negativa do corpo gordo, cria-se o estigma da gordofobia: uma discriminação estrutural e cultural capaz de excluir socialmente as pessoas gordas. A consequência para esse fenômeno é a falta de acessibilidade a essas pessoas (JIMENEZ-JIMENEZ, 2020).

De gorda a plus size desvenda a concepção moderna de corpo, isto é, a ideia de corpo como mecânico e dualista, com base no modelo de racionalidade criado na Idade Moderna: feio ou bonito, doente ou saudável, bom ou ruim, magro ou gordo etc. Uma consequência dessa concepção dualista é o entendimento do corpo magro como desejável e do corpo gordo como doente. A autora reflete sobre como o meio publicitário capitaliza essa ideia ao oferecer um universo de produtos para a obtenção de um corpo desejável a qualquer custo: o magro.

O consumo, portanto, é concebido como cultura e como comportamento, os quais comunicam pertencimentos, vínculos, distanciamentos e subjetividades. Desse modo, leva-se em consideração tudo aquilo relacionado a esta ação imprescindível em nossa sociedade: o comprar. Assim, o desejo, a oferta, o marketing, a publicidade e as representações desse nicho ocorrem por meio do que se quer consumir.

Assistimos, porém, a um movimento de resistência de mulheres gordas que começam a usar, nos espaços públicos, minissaias e tops cropped, expondo suas pernas, barrigas e coxas. Mulheres que vão à praia de biquíni e se libertam, de alguma maneira, desse lugar de dor, sofrimento, humilhação e escárnio. Ressalte-se, porém, que essas mulheres são uma minoria privilegiada, com acesso a um arsenal intelectual biopolítico para formular esses questionamentos, apesar do sistema "magro opressor". 
Compreende-se, destarte, que o ativismo gordo vai muito além da estética e da possibilidade de vestir uma roupa em que a pessoa gorda se sinta linda e maravilhosa. No entanto, não há como negar que ele é, sim, transpassado por essa ação, porém, sabe-se (e se defende) que a estética é política para esses corpos, uma vez que sentir-se bem e bonita, em um mundo onde sempre lhe foi negado esse sentimento, é, de alguma maneira, revolucionário e, portanto, político. Joice Berth (2018) explica, em seu livro, sobre empoderamento e como nossa visão sobre nós mesmos é influenciada diretamente por essa padronização estabelecida e estigmatizante da moda, da mídia, da política e da área da saúde.

O corpo configura-se como importante propagador da publicidade e do marketing de produtos, isto é, na formatação da ideia daquilo que se pretende vender. Via de regra, os corpos apresentados em comerciais e em campanhas publicitárias ainda são de mulheres magras, brancas e sensualizadas. No entanto, surge, a partir do final do século XIX, de forma crescente, a representação da diversidade na comunicação publicitária para estimular práticas de consumo desses públicos. Percebeu-se, então, que a representação de outros tipos de corpos não apenas impulsionava as vendas, mas também incentivava a compra por mulheres que, anteriormente, não se viam como público-alvo de determinados produtos. Assim, hoje, a diversidade é tida como uma oportunidade de mercado.

Note-se, porém, que a representação do diferente na sociedade capitalista pode proporcionar a mera ilusão de inclusão. Essa ilusão pode gerar, em algumas situações, o entendimento equivocado do diferente, ou, ainda, a apropriação deturpada e distante da realidade dos corpos que se propõe representar. É, enfim, a reprodução do padrão, de alguma maneira (JIMENEZ-JIMENEZ, 2020).

Em contrapartida, parece existir uma tensão nessa proposta de representatividade: apesar dos interesses das grandes corporações em lucrar com a diversidade, a visibilidade que esses corpos vêm ganhando (a partir de suas exposições cada vez mais frequentes) está produzindo efeitos sociais positivos. Entendemos que isso ocorre por consequência do que Hooks (2019) sugere: isto é, aquilo que não vemos, não existe. Por outro lado, aquilo que vemos e com o que nos identificamos passa a nos representar no mundo de alguma maneira.

Diante do exposto, proponho a leitura do livro De gorda a plus size, pois este traz o necessário debate acerca da moda como inclusão dos corpos gordos, além de apresentar a literatura sobre os estudos do corpo gordo sob uma perspectiva norte-americana, relevante, uma vez que os Estados Unidos são pioneiros nesta discussão. Assim, a autora aborda perspectivas teóricas dos fat studies, pouco lidas e discutidas no Brasil. Portanto, os estudos apresentados por Aliana Aires são uma rica contribuição acadêmica e social na discussão sobre a luta do ativismo gordo e dos estudos do corpo gordo, os quais caminham lado a lado e começam a se intensificar em nosso país.

\section{REFERÊNCIAS}

AIRES, Aliana Barbosa. De gorda a plus size: a moda do tamanho grande. São Paulo: Estação das Letras e Cores, 2019.

BERTH, Joice. O que é empoderamento? Belo Horizonte: Letramento, 2018.

HOOKS, Bell. Olhares negros: raça e representação. São Paulo: Elefante, 2019. 